\title{
The Visionary Torch Bearer of Indian Agriculture: Prof. Virender Lal Chopra
}

\author{
Vipin Chandra Kalia ${ }^{1}$
}

(C) Association of Microbiologists of India 2020

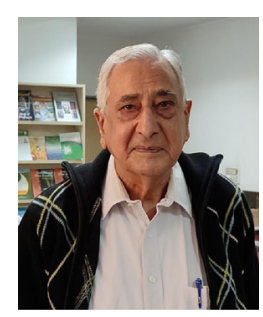

Prof. Virender Lal Chopra (09.08.1936-18.04.2020)

Indian science will always remain grateful to Smt. Sukhwanti and Shri Harbans Lal Chopra, the proud parents of Prof. Virender Lal Chopra, the son who came to be known as the son of Indian Agriculture. Born on 9th August 1936, he started his journey in Indian agriculture, when he secured his B.Sc. (Ag.) from Central College of Agriculture, Delhi and Ph.D. in Genetics from the University of Edinburgh, UK in 1967. He went on to become the Director, Indian Agricultural Research Institute (I.A.R.I.), New Delhi at the age of 43 where the eminent professor steered the research and development in genetics and biotechnology. Other positions of eminence held by Prof. Chopra include Adviser at UN Food and Agriculture Organization; Secretary to Government of India; Director-
General of the Indian Council of Agricultural Research (I.C.A.R.); and Member, Planning Commission of Government of India. He was also Chancellor at Central University, Kerala.

Among many of the prestigious awards that Prof. Chopra was honored with, the Padma Bhushan winner was also awarded Borlaug Award, Om Prakash Bhasin Award, Federation of Indian Chamber of Commerce and Industry (F.I.C.C.I.) Award, Honor Summus Medal, INSA Silver Jubilee Commemoration Medal, INSA Aryabhatta Medal, FAO World Food Day Award, NAAS Dr. B. P. Pal Award, ISCA Birbal Sahni Birth Centenary Award, for his outstanding contributions to science and agriculture.

Author to many books and articles in the area of Crop Genetics and Plant Biotechnology, the Professor was an elected Fellow of many scientific bodies such as The Indian National Science Academy (INSA); The National Academy of Sciences, India (NASI); The National Academy of Agricultural Sciences (NAAS); The Indian Academy of Sciences (IAS); The World Academy of Sciences (TWAS); and honorary doctorates of Chandra Shekhar Azad University of Agriculture and Technology and Banaras Hindu University, to name a few.

On April 18th 2020, the immortal soul of the torch bearer of Indian agriculture has been destined for eternity.

Vipin Chandra Kalia

vckaliaku@gmail.com

1 Department of Chemical Engineering, Konkuk University, 1 Hwayang-Dong, Gwangjin-Gu, Seoul 05029, Republic of Korea 